\title{
ОБОСНОВАНИЕ ИСПОЛЬЗОВАНИЯ РЕЗУЛЬТАТОВ ЛЕТНЫХ ИСПЫТАНИЙ ЛЕТАТЕЛЬНЫХ АППАРАТОВ ПРИ ПРОВЕДЕНИИ СТЕНДОВЫХ ВИБРАЦИОННЫХ ИСПЫТАНИЙ
}

\author{
Минина Любовь Сергеевна \\ ФГБОУВО «Московский авиационный институт \\ (национальный исследовательский университет)»
}

Аннотация: целью статьи является демонстрация проведенного исследования особенностей различных типов вибрационных испытаний летательных аппаратов и обоснование необходимости перехода к использованию акселерограмм с данными полетов при проведении вибрационных испытаний бортового оборудования летательных аппаратов.

Ключевые слова: вибрационные испытания, полевые испытания, вибростойкость, летательный аппарат, VisAnalyzer.

\section{SUBSTANTIATION OF USING THE RESULTS OF FLIGHT REPLICATION DURING STAND VIBRATION TESTS}

\section{Minina Liubov Sergeevna}

Abstract: The purpose of this work is to demonstrate conducted research about the features of various types vibration tests of aircraft and justify the need to switch to the use of accelerograms with flight data when conducting vibration tests of aircraft onboard equipment.

Key words: vibration tests, field replication tests, vibration resistance, flying vehicle, VisAnalyzer.

Создание новых конструкций современных летательных аппаратов тесно образом связано с исследованиями влияния колебательных нагрузок на элементы, узлы, агрегаты и аппарат в целом. Такая связь объясняется ростом мощности двигательных установок, сложной компоновкой частей летательного аппарата, скоростями полёта, увеличением ресурса и надёжности эксплуатации, обеспечением устойчивости и управляемости систем [1, c. 4]. 


\section{ВСЕРОССИЙСКИЙ ИССЛЕДОВАТЕЛЬСКИЙ ФОРУМ

Любое изделие в процессе эксплуатации испытывает вибрационные воздействия в широком спектре частот. Соответственно, при проведении стендовых испытаний необходимо как можно точнее воспроизвести имитацию этого воздействия на испытуемое изделие.

Существующие синтетические испытания - синусоидальным сигналом, широкополосной случайной вибрацией (ШСВ), удары разных форм, более сложные виды (наложения и т.д.) - позволяют только приблизительно сымитировать реальные воздействия с определенной степенью достоверности. Испытания изделий с использованием записанной, например, в полете, акселерограммой (т.е. записью колебаний) реального воздействия позволяют на порядок точнее воспроизвести воздействия, возникающие в процессе реальной эксплуатации и, следовательно, провести испытания на качественно новом уровне. В последнее время такая возможность появилась благодаря разработке компактных цифровых магнитофонов и цифровых систем управления виброиспытаниями.

Таким образом, на сегодняшнем этапе развития авиационно-космической техники, проведение испытаний на воздействие вибрационной нагрузки, с воспроизведением записей реальных воздействий являются одним из наиболее перспективных направлений для изучения.

Целью работы является исследование и обоснование необходимости перехода к использованию акселерограмм с данными реальных полетов при проведении вибрационных испытаний бортового оборудования летательных аппаратов.

Основное назначение вибрационных испытаний - это проверка и обеспечение работоспособности и надёжности разрабатываемых летательных аппаратов. С помощью этих испытаний проверяется состояние и характеристики элементов аппарата. При отклонении отдельных характеристик от заданных величин, выявленных в процессе испытаний, производится их доводка до требований технического задания.

Испытательное оборудование - это средство испытаний, представляющее собой техническое устройство для воспроизведения условий испытаний. При помощи испытательного оборудования воспроизводят как отдельные воздействующие факторы, так и их сочетания.

Проверка продукции на воздействие вибраций производится с помощью вибрационных установок (рис.1). 


\title{
ВСЕРОССИЙСКИЙ ИССЛЕДОВАТЕЛЬСКИЙ ФОРУМ СТУДЕНТОВ И УЧАЩИХСЯ
}

\begin{abstract}
Основными компонентами вибрационной испытательной системы являются:

1) стенд, на который крепят испытуемый объект и датчикиакселерометры;

2) усилитель, его главная задача - подвести необходимую мощность к стенду;

3) система управления вибрацией, которая предназначена для управления
\end{abstract} ходом испытаний в соответствии с заданными пользователем параметрами, а также аварийного останова в случае необходимости;

4) компьютер, с помощью которого пользователь может установить задания, и который отображает результаты проводимого испытания - графики измерений, погрешности и т.д. и управляет ходом испытания.

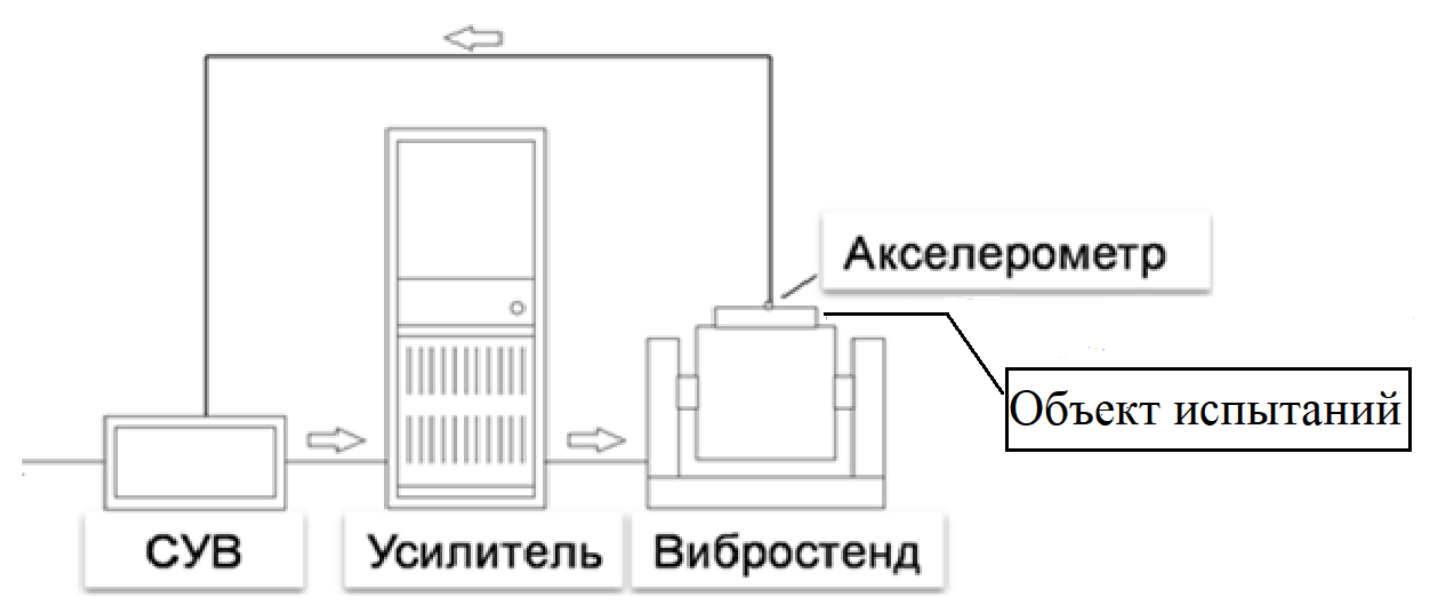

\section{Рис. 1. Схема вибрационной испытательной системы}

После запуска испытания, система управления виброиспытания (СУВ) подает на стенд сигнал малого уровня, постепенно повышая до уровня, заданного пользователем. В ходе испытания СУВ изменяет сигнал, подаваемый через усилитель на объект, таким образом, чтобы сигнал с акселерометра соответствовал заданию пользователя. Также она следит за правильностью хода испытания - проверяет, не превысили ли значения ускорения на стенде допустимые пределы [2, стр. 23-29].

Вибростойкостью называется способность летательного аппарата, его систем и аппаратуры сохранять работоспособность в условиях воздействия вибрации [3, стр. 4]. 


\section{ВСЕРОССИЙСКИЙ ИССЛЕДОВАТЕЛЬСКИЙ ФОРУМ

В настоящее время существует множество типов испытаний изделий на вибростойкость, однако все из них можно разделить на три типа:

1) испытания, в которых на объект воздействуют сигналом, описываемым базовой математической моделью - синус, ШСВ, классический удар;

2) испытания, в которых на объект воздействуют сигналом, описываемым совокупностью двух или трех базовых моделей - смешанные испытания;

3) испытания, в которых на объект воздействуют сигналом, описываемым акселерограммой (испытания с воспроизведением заданной акселерограммы). При этом акселерограмма чаще всего не может быть описана ни одной из базовых моделей или их совокупностью.

Рассмотрим третий тип испытаний и способы оценки их воспроизводимости на примере системы управления виброиспытаниями ВС-301. СУВ ВС-301 выбрана для примера потому, что она реализуют все существующие типы испытаний [2, стр. 23-29].

Запись данных в реальном полете вертолета проводилась с помощью комплекса «Мобильный диагностический ВС-311» (рис.2).

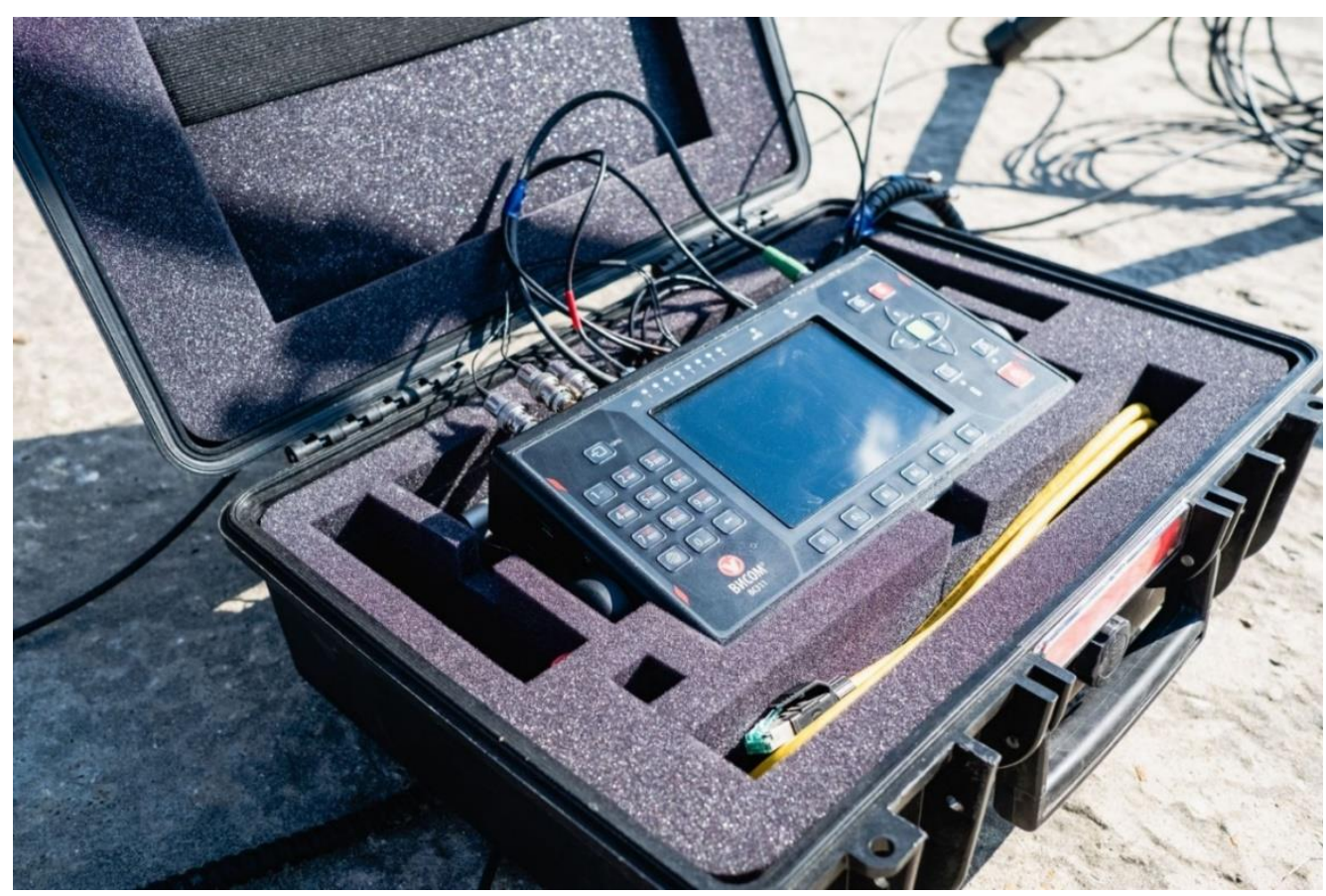

Рис. 2. Комплекс виброналадки ВС-311

При проведении испытаний акселерометр крепился под креслом пилота. При испытаниях использовался трехкомпонентный акселерометр, 
позволяющий одновременно определять вертикальную, поперечную и осевую составляющие вибрации. В ходе проведения эксперимента в различных режимах полета и висения были произведены записи данных вибрации (табл. 1 и табл. 2).

\section{Таблица 1}

Уровни вибрации на оборотной частоте

\begin{tabular}{|c|c|c|c|c|c|c|c|c|}
\hline \multirow[t]{2}{*}{ Режим } & \multicolumn{2}{|c|}{ Частота вращения } & \multicolumn{2}{|c|}{ Вертикальная } & \multicolumn{2}{|c|}{ Поперечная } & \multicolumn{2}{|c|}{ Осевая } \\
\hline & Гц & Об/мин & $\begin{array}{c}\text { A, } \\
\text { мкм }\end{array}$ & $\begin{array}{c}\text { Фаза, } \\
\text { градусы }\end{array}$ & $\begin{array}{c}\text { A, } \\
\text { мкм }\end{array}$ & $\begin{array}{c}\text { Фаза, } \\
\text { градусы }\end{array}$ & $\begin{array}{c}\text { A, } \\
\text { мкм }\end{array}$ & $\begin{array}{c}\text { Фаза, } \\
\text { Градусы }\end{array}$ \\
\hline Висение & 4,45 & 267,0 & 36 & 284 & 26 & 240 & 468 & 294 \\
\hline $150 \mathrm{\kappa M} / \mathrm{ч}$ & 4,53 & 271,8 & 164 & 278 & 60 & 157 & 70 & 268 \\
\hline $180 \mathrm{\kappa M} / \mathrm{ч}$ & 4,54 & 272,4 & 162 & 276 & 64 & 161 & 58 & 269 \\
\hline 200 км/ч & 4,54 & 272,4 & 207 & 275 & 118 & 169 & 58 & 270 \\
\hline $240 \mathrm{\kappa м} / \mathrm{ч}$ & 4,57 & 274,2 & 242 & 279 & 127 & 252 & 94 & 279 \\
\hline
\end{tabular}

Таблица 2

Уровни вибрации на лопастной частоте

\begin{tabular}{|c|c|c|c|c|c|}
\hline \multirow{2}{*}{ Режим } & \multicolumn{2}{|c|}{ Частота вращения } & $\begin{array}{c}\text { Вертикальная } \\
\text { А, мкм }\end{array}$ & $\begin{array}{c}\text { Поперечная } \\
\text { А, мкм }\end{array}$ & $\begin{array}{c}\text { Осевая } \\
\text { А, мкм }\end{array}$ \\
\hline Висение & 4,45 & 267,0 & 9 & 11 & 10 \\
\hline 150 км/ч & 4,53 & 271,8 & 42 & 19 & 29 \\
\hline 180 км/ч & 4,54 & 272,4 & 122 & 16 & 94 \\
\hline 200 км/ч & 4,54 & 272,4 & 198 & 10 & 177 \\
\hline 240 км/ч & 4,57 & 274,2 & 290 & 71 & 454 \\
\hline
\end{tabular}

На (рис. 3-5) приведены спектры вибрации по вертикальной составляющей в размерности амплитуды виброперемещения (она показывает максимальную амплитуду перемещения контролируемых точек при заданных параметрах вибрации) в диапазоне частот 2-20 Гц. 


\section{ВСЕРОССИЙСКИЙ ИССЛЕДОВАТЕЛЬСКИЙ ФОРУМ \\ СТУДЕНТОВ И УЧАЩИХСЯ}

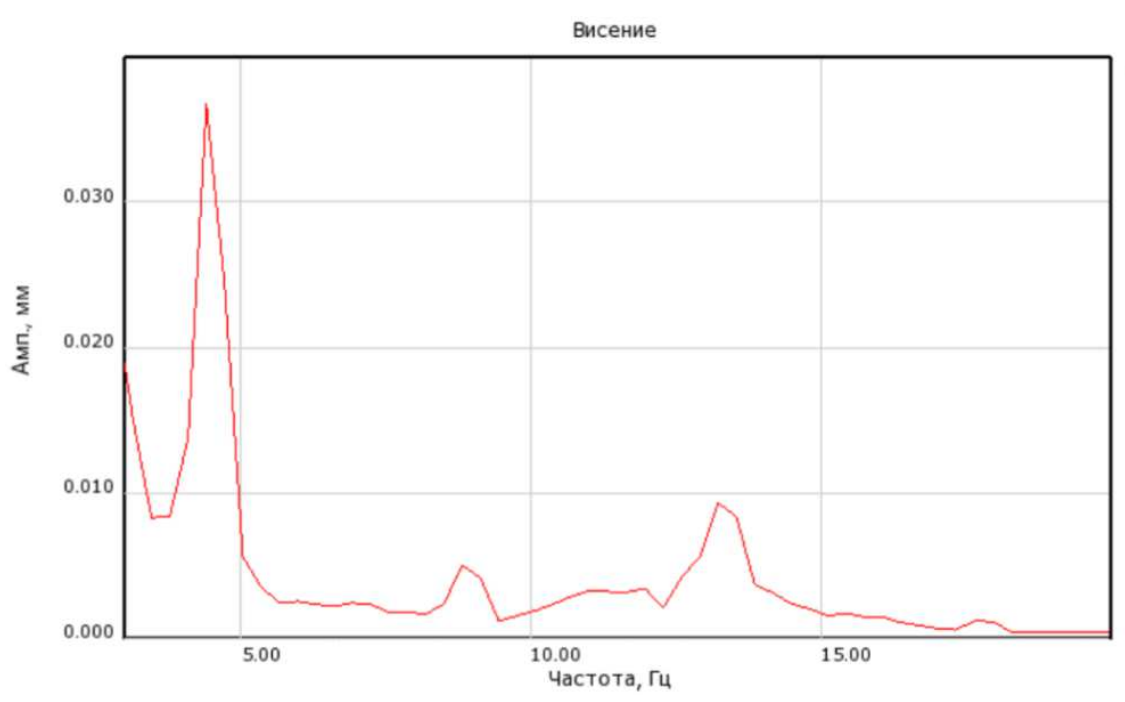

Канал 3 дИнт Ам

Рис. 3. Режим «Висение»

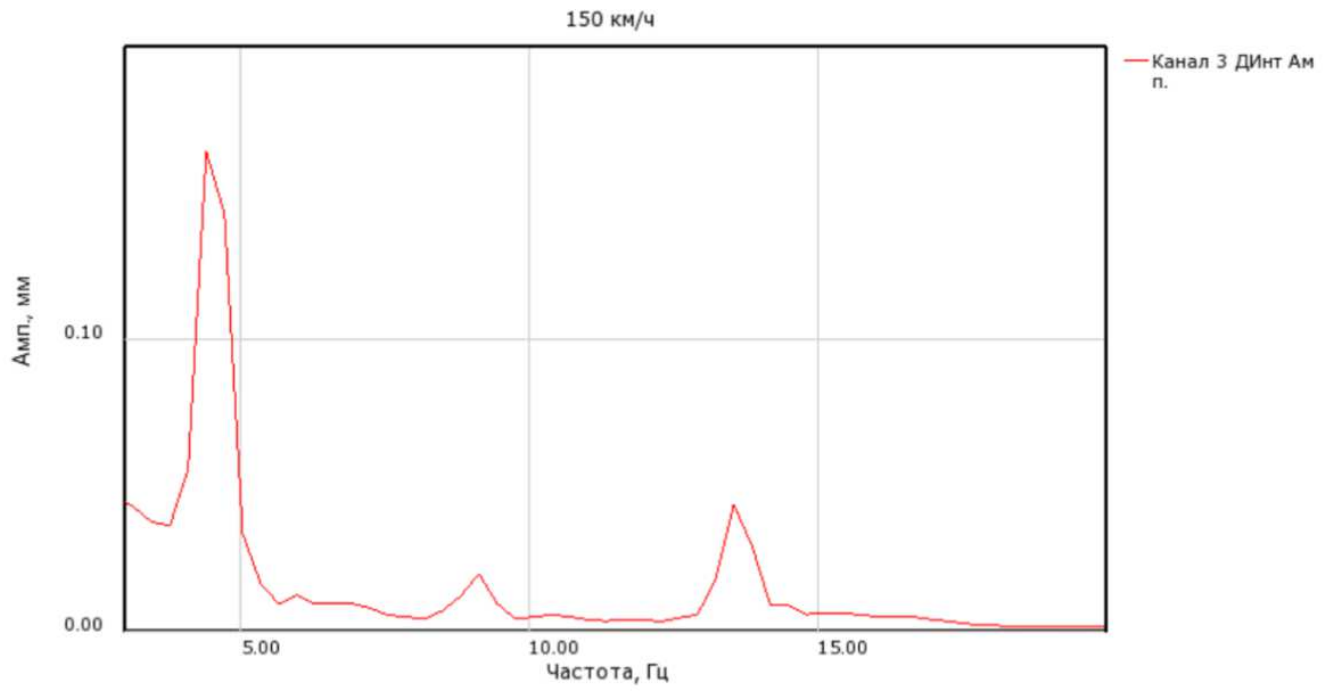

Рис. 4. Режим «150 км/ч»

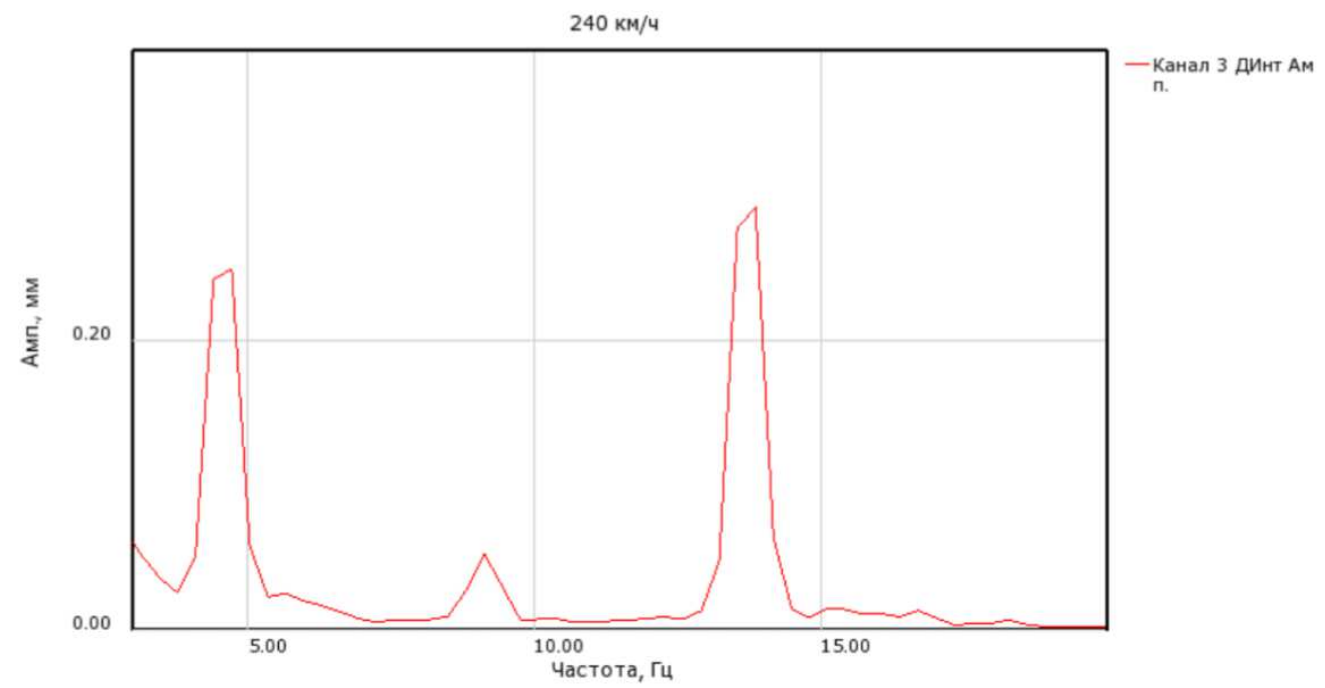

Рис. 5. Режим «240 км/ч» 
На (рис. 6-9) приведены спектры виброускорения (т.е. значения вибрации, напрямую связанные с силой, которая вызвала вибрацию) в единицах спектральной плотности мощности (мощность, которая приходится на единичный интервал частоты) для вертикальной составляющей в режимах «Висение», «150 км/ч» и «240 км/ч».

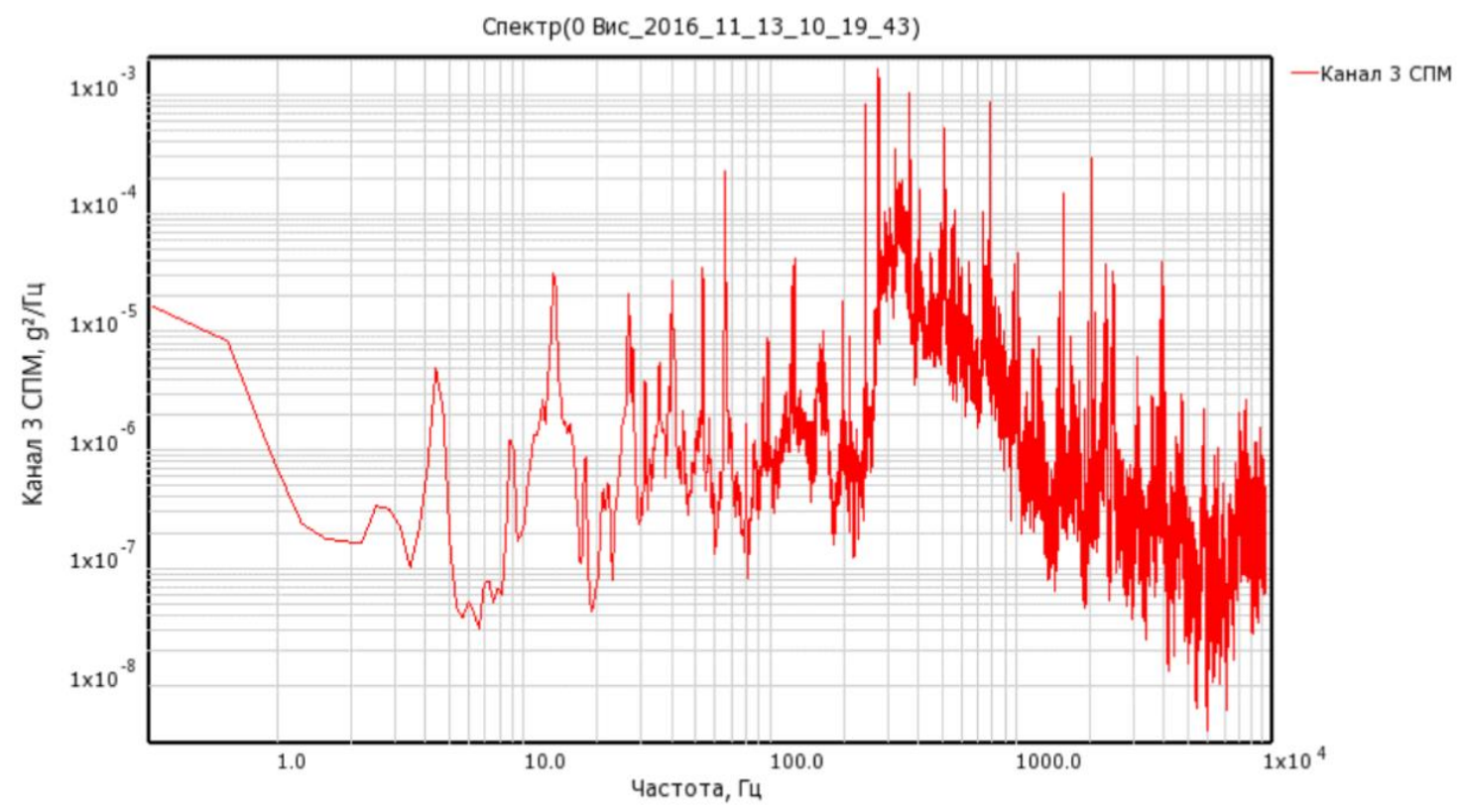

Рис. 6 Спектрограмма, режим «Висение»

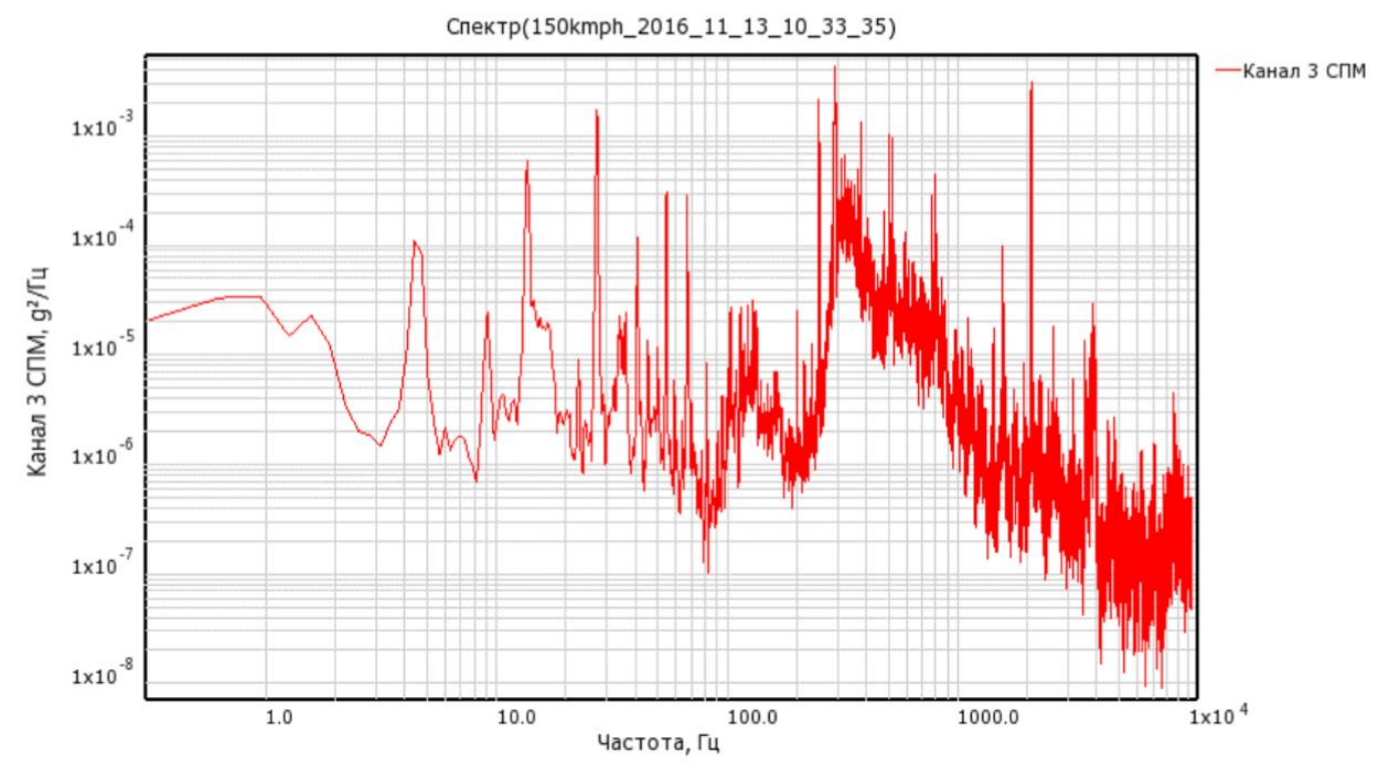

Рис. 7. Спектрограмма, режим «150 км/ч» 


\section{ВСЕРОССИЙСКИЙ ИССЛЕДОВАТЕЛЬСКИЙ ФОРУМ

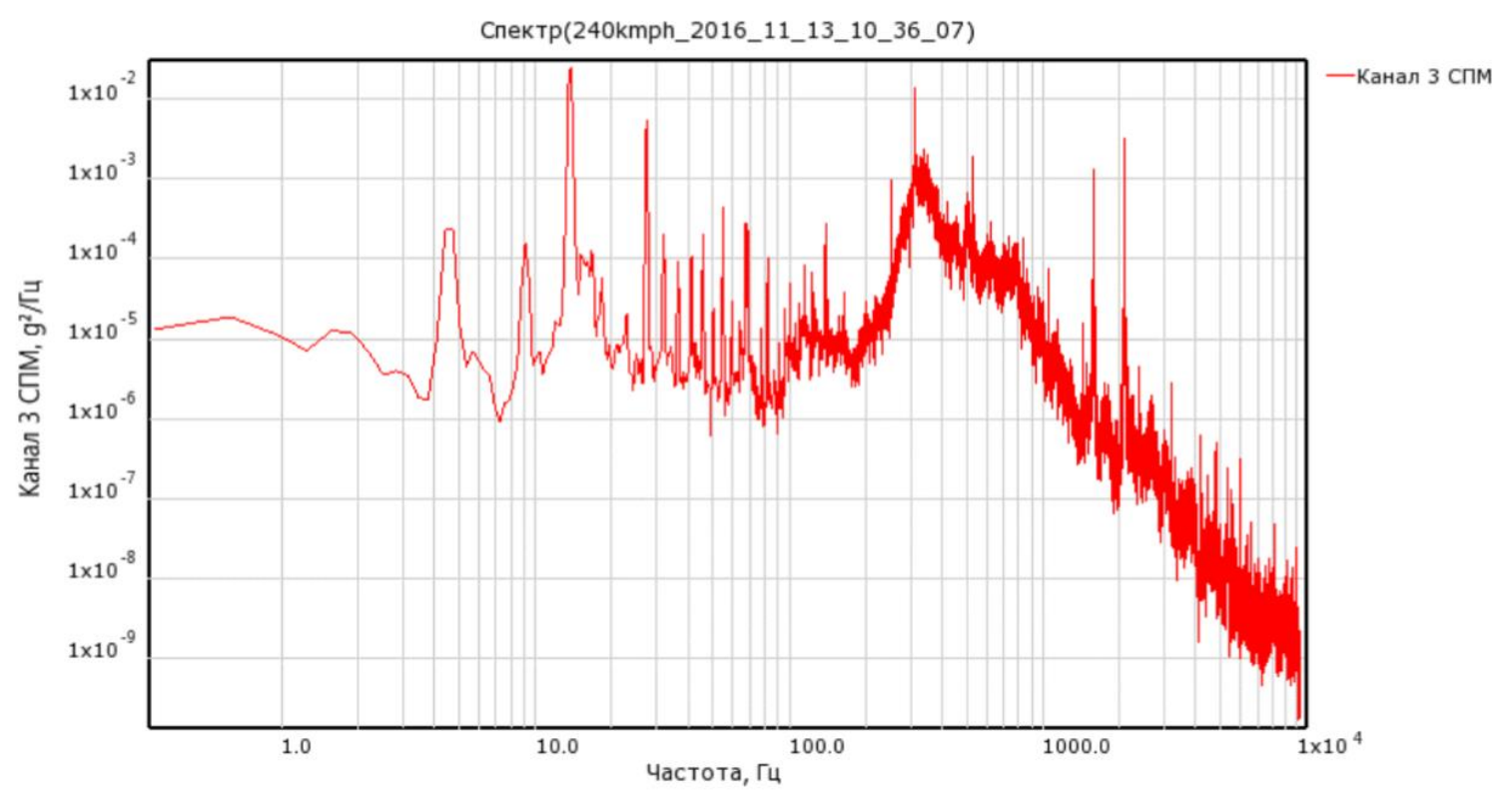

Рис. 8. Спектрограмма, режим «240 км/ч»

Полученные записи были обработаны с помощью программ «VisAnalyser» и «MATLAB» в целях получения обобщенной акселерограммы воздействия на оборудование вертолета в различных режимах полета.

В настоящее время для вибрационных испытаний бортовой аппаратуры вертолетов рекомендуются тесты, описанные в стандартах RTCA/DO-160 [4, стр. 1- 331], MIL-STD-810G [5, стр. 1-804] и соответствующих национальных аналогах.

В соответствии с секция 8 «Vibration» стандарта RTCA/DO-160, для испытаний вертолетной бортовой аппаратуры в режимах «Синусоидальная вибрация» и «Наложение синуса на ШСВ» рекомендуется проводить испытания в соответствии с профилями испытаний, представленных ниже (рис. 9 и рис.10). 


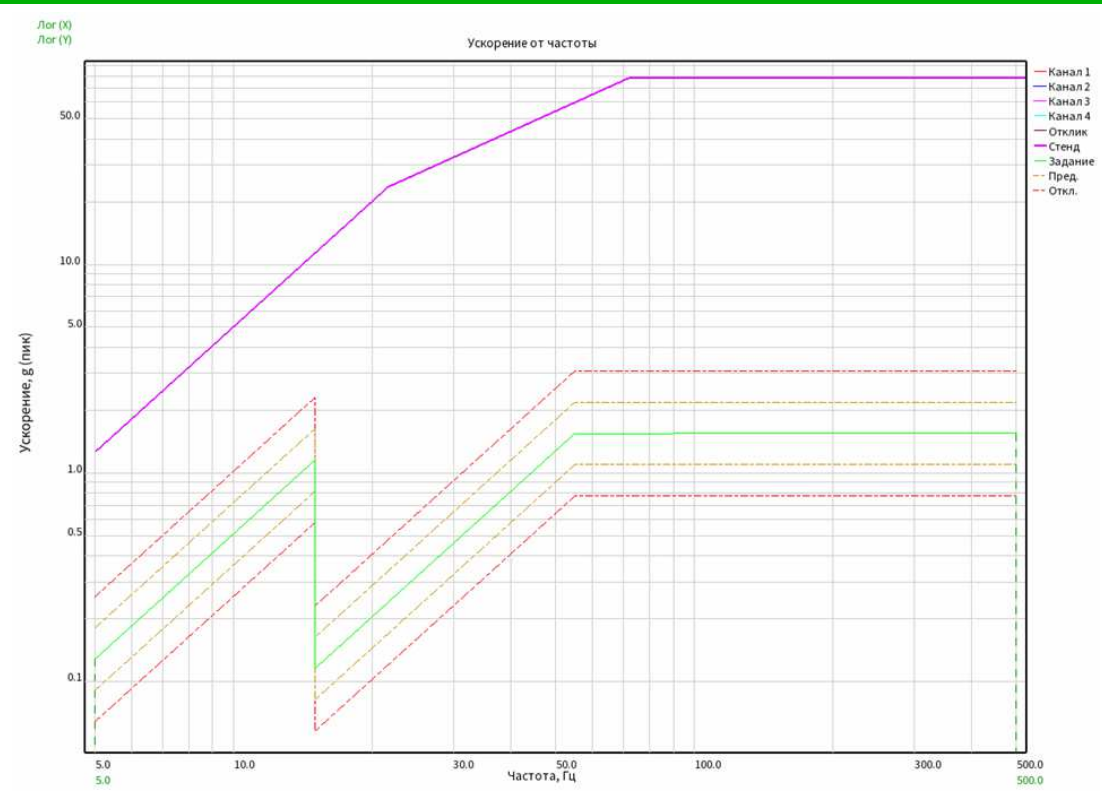

Рис. 9. Профиль испытаний в режиме "Синусоидальная вибрация"

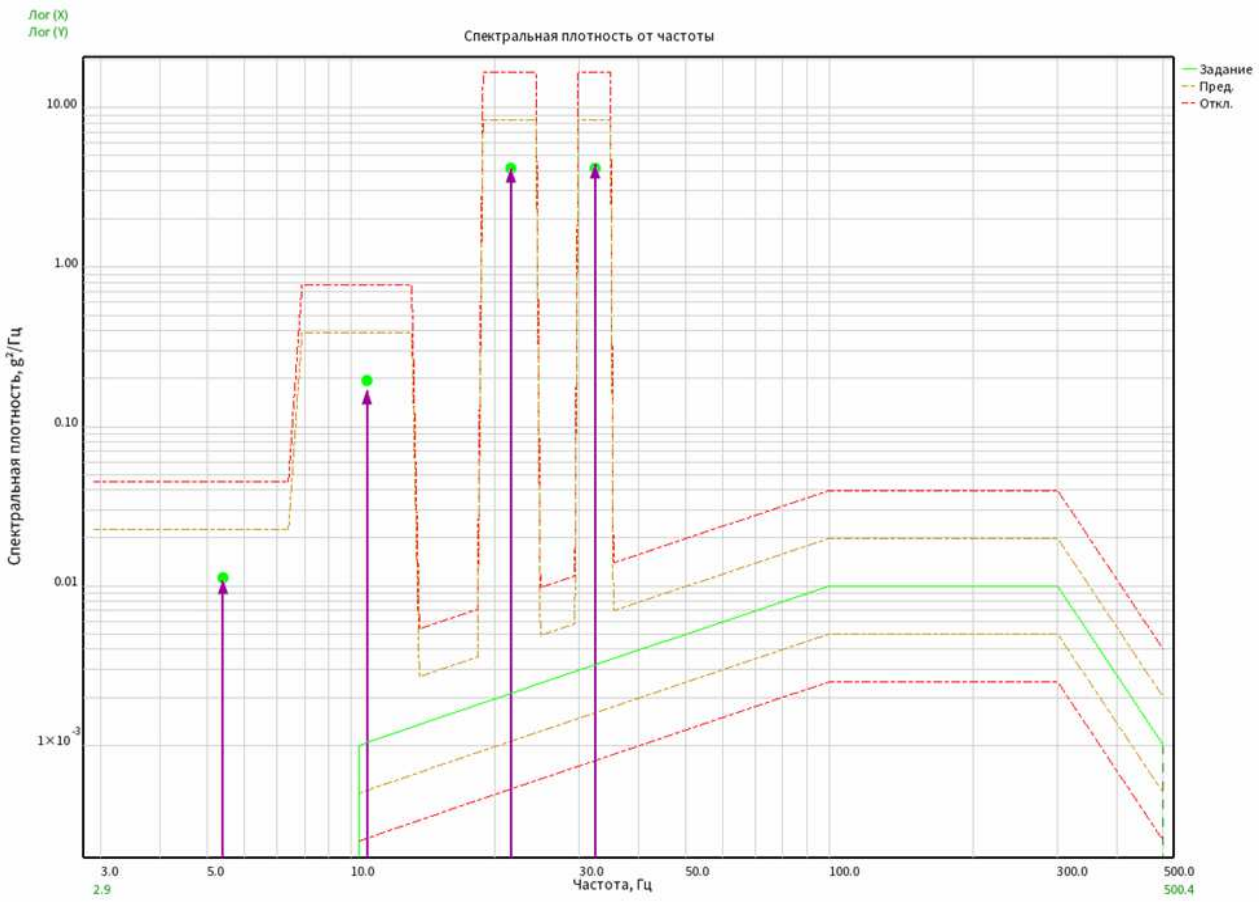

Рис. 10. Профиль испытаний в режиме "Наложение синуса на ШСВ" в соответствии со стандартом RTCA/DO-160

Как видно из графика на рисунке 10 , на профиль ШСВ рекомендуется накладывать тона синуса 12, 30, 90 и 110 Гц. В результате осреднения данных реального полета вертолета в различных режимах построен усредненный график воздействия (рис.11). 


\section{ВСЕРОССИЙСКИЙ ИССЛЕДОВАТЕЛЬСКИЙ ФОРУМ СТУДЕНТОВ И УЧАЩИХСЯ}

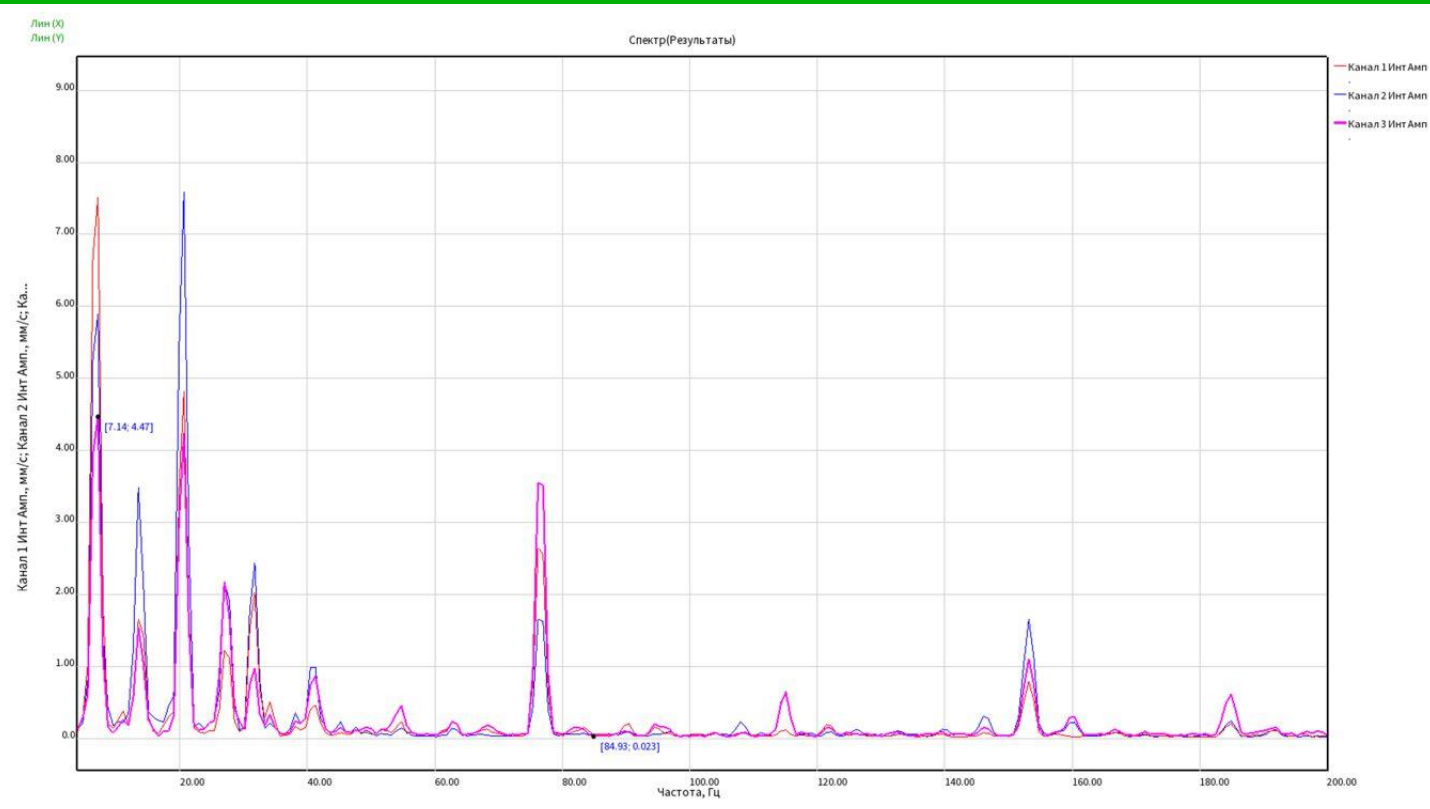

Рис. 11. Усреднённый график воздействия

Из графика на рисунке 11 видно, что присутствуют дополнительные тона воздействия синуса на частотах $5,12,21,78$ и 153 Гц.

Таким образом, в ходе исследования был проведен анализ данных вибрации, которые были записаны в ходе реальных полетов вертолета, а также проведен анализ записей. В результате анализа, который проводился с помощью пакетов «MATLAB» и «VisAnalyser», получена обобщенная акселерограмма вибрационного воздействия на бортовое оборудование в различных режимах полета.

Сравнение полученной акселелограммы с существующей нормативной документации по проведению наземных вибрационных испытаний показало наличие дополнительных факторов вибрационного воздействия на аппаратуру в ходе реальной эксплуатации летательных аппаратов.

Итогом работы являются рекомендации по проведению наземных вибрационных испытаний бортовой аппаратуры летательных аппаратов с использованием усредненной акселерограммы воздействия, полученной в ходе реальных полетов. Такой подход позволяет улучшить качество проведения наземных вибрационных испытаний, повысить надежность бортового оборудования летательных аппаратов и, в конечном итоге, повысить безопасность полетов. Особенностью работы является исследование записей вибрационного воздействия на различных летательных аппаратах и уточнение 


\section{ВСЕРОССИЙСКИЙ ИССЛЕДОВАТЕЛЬСКИЙ ФОРУМ СТУДЕНТОВ И УЧАЩИХСЯ}

программ и методики испытаний при наземных испытаниях на базе акселерограмм воздействия на бортовую аппаратуру в реальных условиях.

На основании полученных результатов можно сделать вывод о необходимости проведения наземных испытаний бортовой аппаратуры с воспроизведением данных, которые получены в реальном полете на различных режимах.

\section{Список литературы}

1. Афанасьев, В. А. Испытания летательных аппаратов при воздействии ударных нагрузок [Текст]: учеб. пособие/ В.С. Барсуков, М. Я. Гофин, Ю.В. Захаров. - М.: Изд-во МАИ, 1990. - 56 с.

2. Кулак В. А., Соколов И.Н. Современный подход к виброиспытаниям: переход от абстракций к реальным данным [Текст]// Вестник метролога, № 1, 2008. с. 23-29.

3. ГОСТ 24346 - 80 (СТ СЭВ 1926 -79). Вибрация. Термины и определения; введ. 01.01.81. - Москва: Изд-во стандартов, 1980. - 32 с.

4. RTCA/DO-160 Environmental Conditions and Test Procedures for Airborne Equipment; введ. 28.02.1975. - Radio Technical Commission for Aeronautics (RTCA EUROCAE), 1975, $331 \mathrm{c}$.

5. MIL-STD-810G Environmental Engineering Considerations and Laboratory Tests; введ. 31.10.2008. - Department of Defense Test Method Standart, 2008, 804 c. 